\title{
Analysis and design of the tower pier anchor of steel tower cable stayed bridge
}

\author{
Dong-li Sun ${ }^{1, a^{*}}$, Bin Xie ${ }^{1, b}$, Xu kai Liu ${ }^{1}$ and Jing Cao ${ }^{1}$ \\ ${ }^{1}$ Tianjin Municipal Engineering Design \& Research Institute, No. 239 Yingkou Street, Heping \\ District, Tianjin, 300051, China

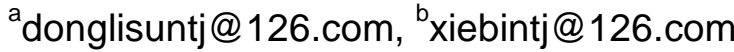

Keywords: Bridge engineering, Cable stayed bridge, Tower pier anchor, Entity analysis.

Abstract. The No.4 bridge of Erdos Wulanmulun River city is a steel-concrete composite beam of cable stayed bridge. The Twin Towers bridge with double cable planes, tower adopts steel bridge tower. This paper introduces the design of structural steel pylon pier anchor and computational analysis of the situation. This research achievement can provide us with a reliable reference for similar projects.

\section{Introduction}

The No. 4 Bridge of Wulanmulun River is located in Kangbashi New District Erdos City, acrossing the Wulanmulun River. Kangbashi new district is the core area of the "One City and Three Areas city planning", and this district will be the political, economic and cultural center of Erdos City. As the construction of Kangbashi district, the Wulanmulun River will become an important landscape river flowing through the internal city, and will become tourist attractions in Erdos City. So No. 4 Bridge is not only a bridge for traffic function but also for landscape function. At very beginning No. 4 Bridge was planned as a landmark of Erdos City, it should represent the local culture and characteristic. So in order to meet the requirements of the landscape, the pylon of this cable-stayed bridge was designed leaning to the main span and that cause the bridge looks like tow steeds galloping toward each other. The photo of this bridge was shown in Figure 1.

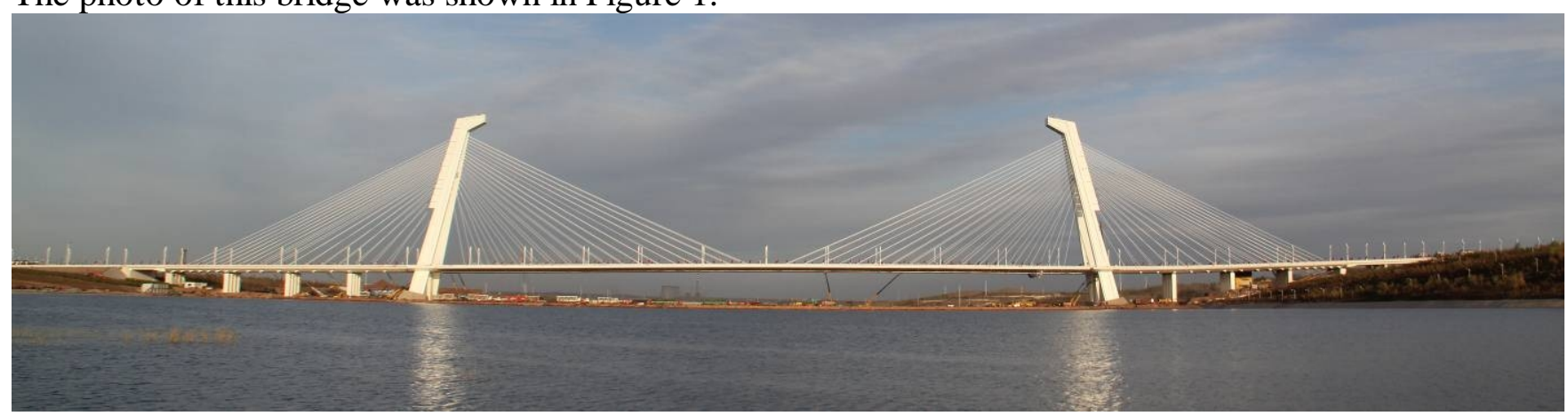

Fig.1 Bridge photo

Because the pylon lean 12 degrees and 130m high, it's very difficult to design and construct it a reinforced concrete structure, steel pylon was adopted.

\section{The General Layout of Main Bridge}

The main bridge of Wulanmulun River No. 4 Bridge is a twin pylon double cable planes cable stayed bridge with hybrid girder, and it is supporting system. the pylon of it was designed leaning 12 degrees to the main span. The span are $(40+42+42+51) \mathrm{m}+450 \mathrm{~m}+(51+42+42+40) \mathrm{m}=800 \mathrm{~m}$, and assistant piers are set at side span, as shown in Fig.2. The hybrid girder is composited with steel-box-girder of $432 \mathrm{~m}$ and prestressed concrete box girder of $368 \mathrm{~m}$ which depth is $3 \mathrm{~m}$. The steel pylon is like " $\mathrm{A}$ " in shape and about $130 \mathrm{~m}$ high. The bridge structure was shown in Figure 2. 


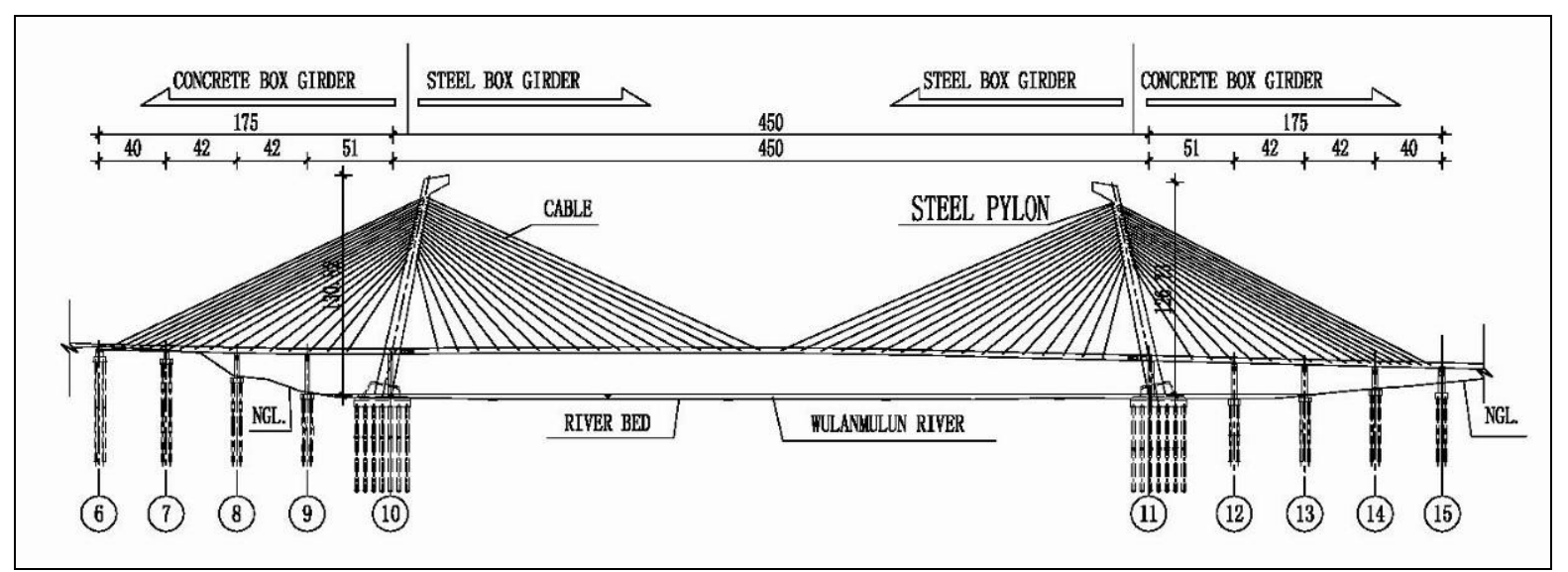

Fig.2 Elevation layout of the cable-stayed bridge

The transect layout is: wind fairing $1 \mathrm{~m}+$ balustrade $0.25 \mathrm{~m}+$ bicycle way and sidewalk $4.5 \mathrm{~m}+$ guardrail $0.5 \mathrm{~m}+$ motorway $12 \mathrm{~m}+$ median strip $0.5 \mathrm{~m}+$ motorway $12 \mathrm{~m}+$ guardrail $0.5 \mathrm{~m}+$ bicycle way and sidewalk $4.5 \mathrm{~m}+$ balustrade $0.25 \mathrm{~m}+$ wind fairing $1 \mathrm{~m}$, the full width is $37 \mathrm{~m}$, as shown in Fig.3.

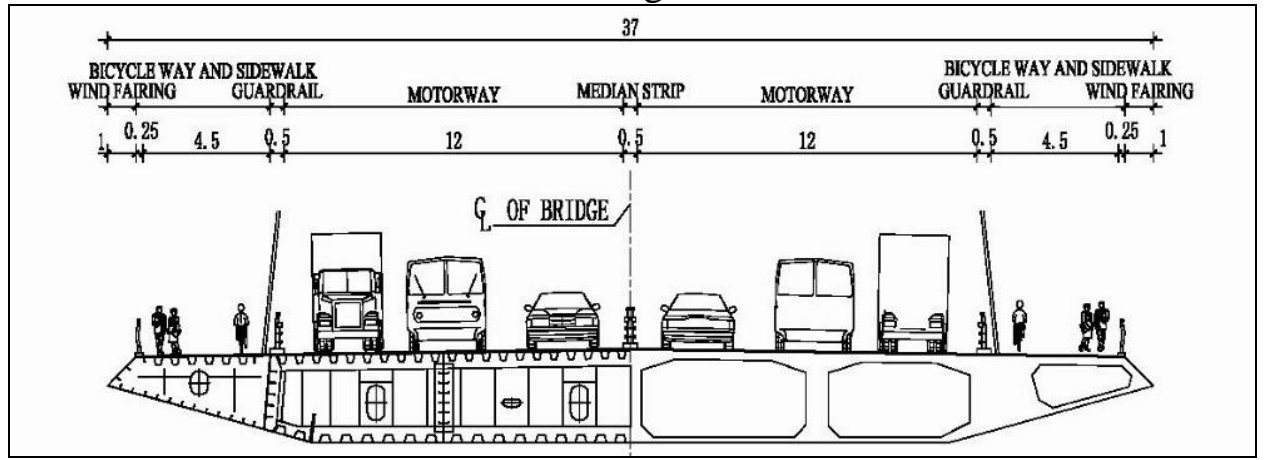

Fig.3 The transect layout of the bridge

\section{Structural Design of the Joint between Steel Pylon and Pile Cap}

As the bridge pylon is made of steel and the pile cap is made of concrete what the most important is to how to join them together. To solve the problem we design a special structure called "pylon boots". The "pylon boots" join the pylon and the pile cap together and through it the force and moment transfer from pylon to pile cap.

The main point of the "pylon boots" structure design is to embed steel pylon into the concrete "pylon boots", integrate the steel pylon and concrete "pylon boots" together whit Cheese head studs, PBL shear connectors and prestressed wire. Besides that, concrete casting into the interior of the steel pylon to give pylon stiffness a gradient. The steel pylon embedded into "pylon boots" for $4 \mathrm{~m}$ and $4 \mathrm{~m}$ from the bottom of pylon C50 expand concrete casting into the pylon. On the embedded part of the pylon there are $60 \mathrm{~mm}$ holes on the panel and reinforce bar with $25 \mathrm{~mm}$ diameter passing through these holes. The hole and the reinforced bar form the PBL shear connectors. Distance between PBL shear connectors is $600 \mathrm{~mm}$. On the surface of the embedded pylon $\Phi 22 \times 170 \mathrm{~mm}$ cheese head studs are arrayed in a distance of $20 \mathrm{~cm} \times 20 \mathrm{~cm}$. Prestressed wires are designed in the "pylon boots" who set from pile cap to top of the "pylon boots" and anchored at "bearing plate" as shown in Fig.4.

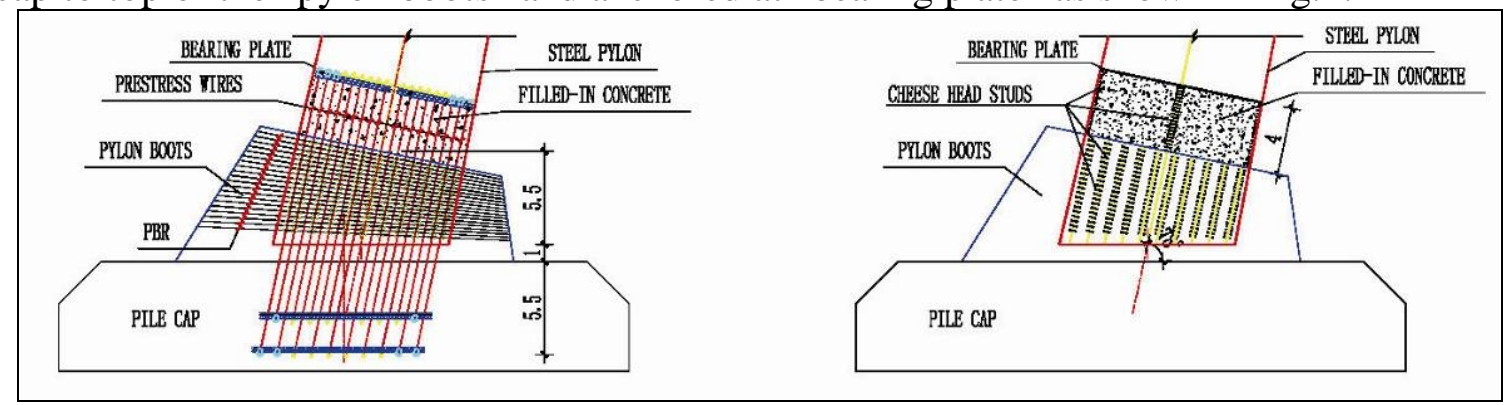

Fig.4 "Pylon boots" elevation layout 


\section{Analysis of "pylon boots"}

FEA Modeling of "pylon boots". To analysis the stress of the "pylon boots", a 3D finite element model is established. According to the Saint Venant's principle, the model for the finite element numerical analysis shall have enough length to avoid the influence causing by boundary condition of the model. So the FEA model has a high of $22 \mathrm{~m}$ which consist of $6.5 \mathrm{~m}$ pile cap, $6.5 \mathrm{~m}$ "pylon boots" and $9 \mathrm{~m}$ steel pylon. The geometric model of pile cap and "pylon boots" is shown in Figure 5.

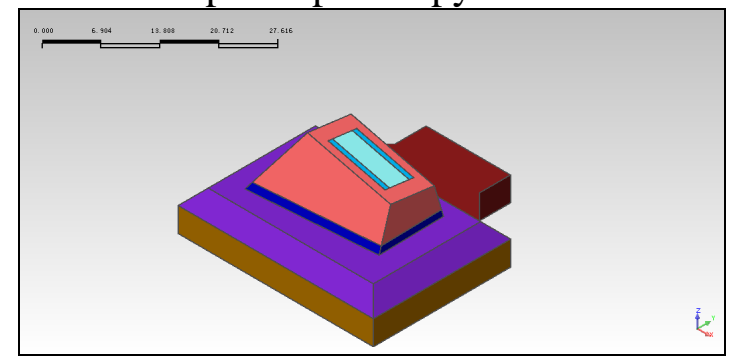

Fig.5 pile cap and "pylon boots" geometric model

The model consisted of 3D hexahedron element which is used to analysis concrete structure of "pylon boots" and tetragon shell element which is used to analysis steel structure of "pylon boots". The entire model is shown in Figure 6 and Figure 7.

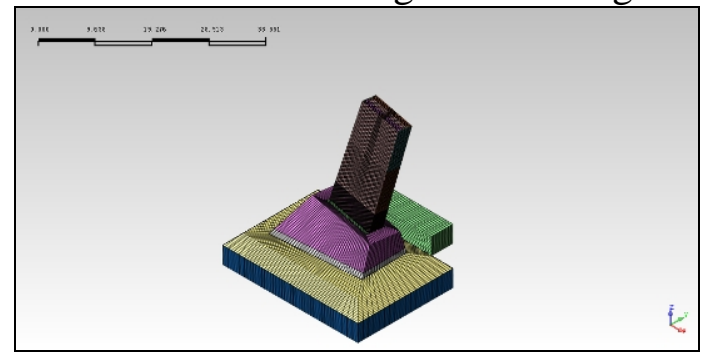

Fig.6 The entire model

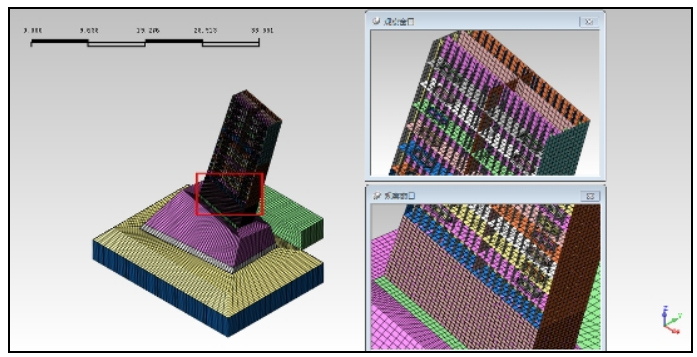

Fig.7 The model for analysis with detail

To simplify the analysis, the model dose not including piles. So rigid support is set at the bottom of the pile cap and at where the pile should be. As there is a "reinforce bar" element in the element library of "MIDAS FEA", we can directly use that element to simulate the prestressed wires in the "pylon boots". There are a total of 108 prestressed wire bunches in the "pylon boots", and shown in Fig.8.

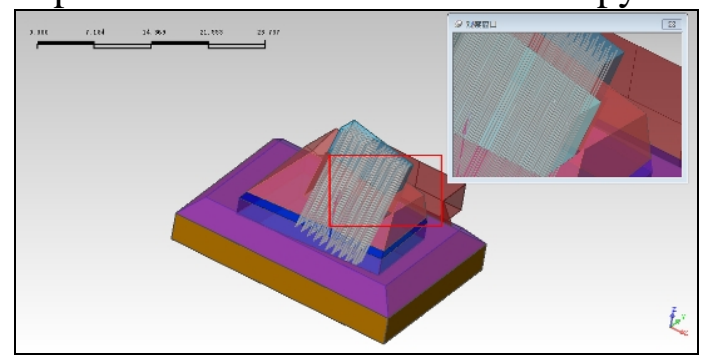

Fig.8 Prestressed wires

Load Analysis of "pylon boots". The load for "pylon boots" analyzing is the result of the overall model of the bridge which is simulated with 3D beam element and the program is Midas Civil 2010. The overall model is shown in Figure 9. Analysis of overall model provide force and moment for pylon boots" analyzing which will act on the top of "pylon boots" FEA model. The force and moment of 6 different load conditions have been calculated and shown in Table 1.

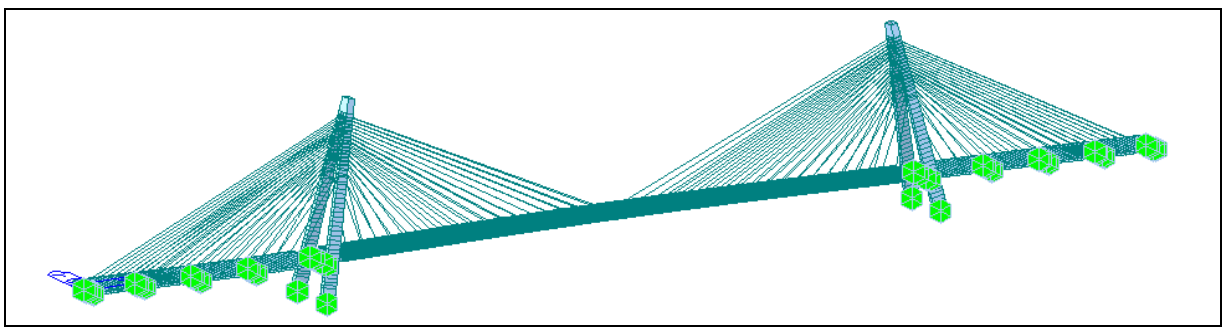

Fig.9 3D beam element model of the overall bridge 
Table 1 The extreme internal force values of $K-k$ cross section under controlled conditions and corresponding concurrent force

\begin{tabular}{|c|c|c|c|c|c|c|c|}
\hline \multicolumn{2}{|c|}{ Condition } & $\begin{array}{c}\text { Axial } \\
{[\mathrm{kN}]}\end{array}$ & $\begin{array}{c}\text { Shear } \\
\text { Force-z } \\
{[\mathrm{kN}]}\end{array}$ & $\begin{array}{c}\text { Shear } \\
\text { Force-z } \\
{[\mathrm{kN}]}\end{array}$ & $\begin{array}{c}\text { Torque-y } \\
{[\mathrm{kN*m}]}\end{array}$ & $\begin{array}{c}\text { Bending } \\
\text { moment-y } \\
{[\mathrm{kN} * \mathrm{~m}]}\end{array}$ & $\begin{array}{c}\text { Bending } \\
\text { moment-z } \\
{\left[\mathrm{kN} \mathrm{k}^{*}\right]}\end{array}$ \\
\hline One & Minimum axial force & -91329 & -466 & 1008 & 1461 & 3271 & -7476 \\
\hline Two & Minimum shear-z & -79792 & -641 & 4106 & 9713 & 162820 & -12266 \\
\hline Three & Minimum shear-y & -79849 & -434 & 4977 & 4444 & 238820 & 11843 \\
\hline Four & Minimum torque-y & -77999 & -471 & 4385 & 10943 & 218182 & 11146 \\
\hline Five & $\begin{array}{c}\text { Maximum bending } \\
\text { moment-y }\end{array}$ & -81778 & -429 & 4811 & 3918 & 247783 & 11902 \\
\hline Six & $\begin{array}{c}\text { Maximum bending } \\
\text { moment-z }\end{array}$ & -83084 & -234 & 86 & -8678 & -29656 & 17488 \\
\hline
\end{tabular}

The results of finite element analysis. To avoid the effect to the stress result of the model causing by boundary conditions, we just see the stress of the concrete between pylon and pile cap ("pylon boot" concrete), stress of filled-in concrete in the pylon and stress of the steel pylon. The maximum stress under different working conditions was shown in Figure 10. The maximum stress result under different working conditions was shown in Figure 11.

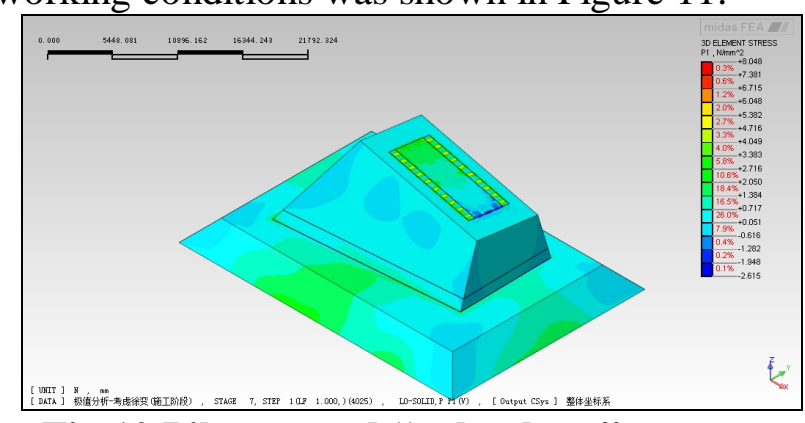

Fig.10 Pile cap and "pylon boot" concrete principal tensile stress nephogram (Mpa)

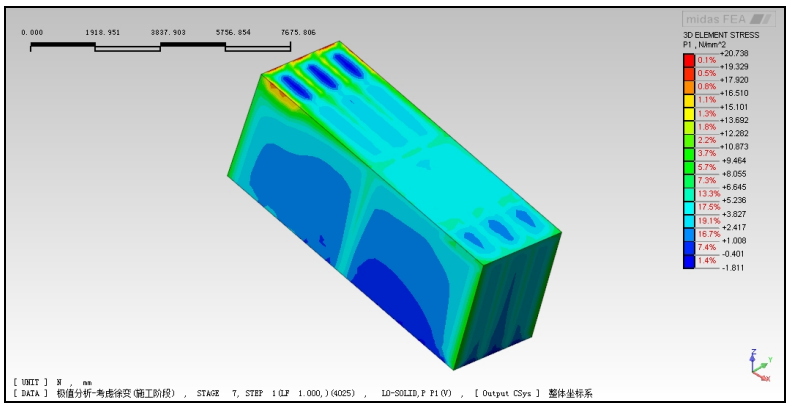

Fig.11 The principal tensile stress nephogram of filled-in concrete in steel pylon (MPa)

As shown in Figure 10 to Figure 11, in most of the pile cap and "pylon boot" concrete, the principal tensile stress are $-0.62 \sim 3.38 \mathrm{MPa}$. Besides some larger partial stress at some corners, the principal tensile stress in most of the filled-in concrete in steel pylon are 2.0 to6.3 MPa, and we can keep the structure safety and reliability with appropriate design of reinforcing bar.

As shown in Figure 12 to Figure 14,the principal tensile stress of the web and transverse plate of the steel pylon are $77.32 \sim 65.01 \mathrm{MPa}$, the tensile stress of "bearing plate" are $42.21 \sim 40.95 \mathrm{MPa}$, and the principal tensile stress of stiffener rib are $-9.55 \sim 52.10 \mathrm{MPa}$, all of the principal tensile stress of steel pylon are less than $210 \mathrm{MPa}$, and meet the specification requirements.

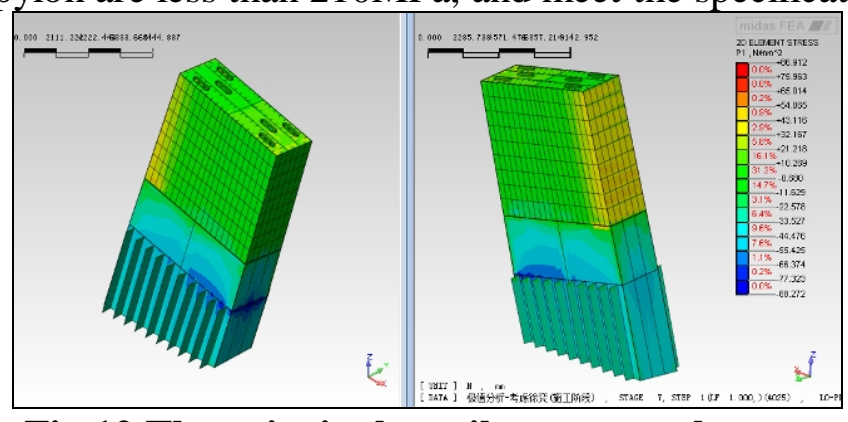

Fig.12 The principal tensile stress nephogram of steel pylon (MPa)

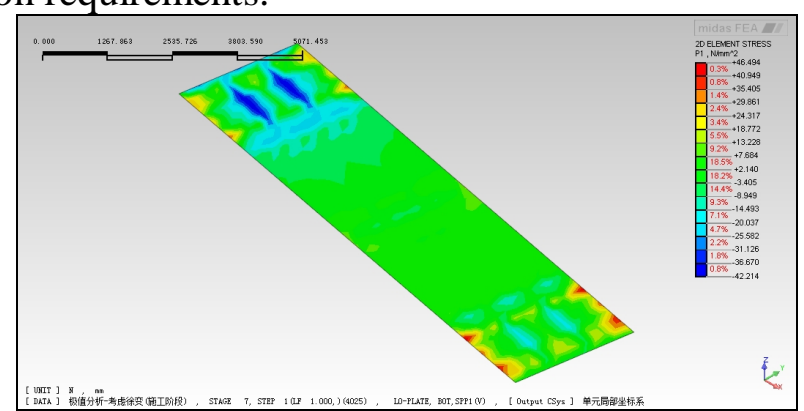

Fig.13 The bearing plate tensile stress nephogram 


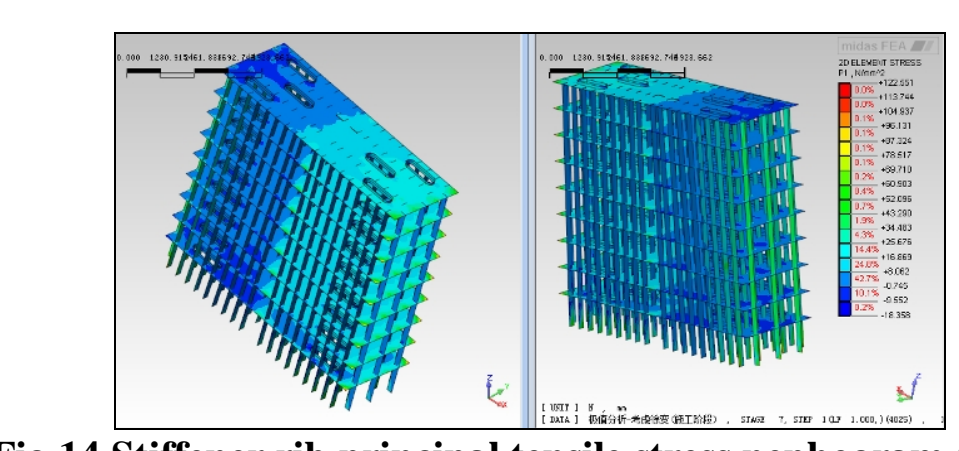

Fig.14 Stiffener rib principal tensile stress nephogram (MPa)

\section{Conclusions}

Due to the landscape requirements, the bridge pylon was designed leaning 12 degree and a steel pylon and that brought the problems of how to join the steel pylon and concrete pile caps safety and reliability. The paper introduces a structure design of the joint of steel pylon and concrete pile cap which called "pylon boots". In the structure, steel pylon embed into the concrete "pylon boots" and filled-in concrete casting in the steel pylon to change the structure stiffness smoothly. And together whit Cheese head studs, PBL shear connectors, PBR, and prestressed wires, the steel pylon and concrete pile cap are jointed together. Finally, through the finite element analysis, we verify the structure design is safety and reliability.

With the development of city construction in our country, more and more steel-concrete hybrid structure will be constructed. I hope the paper is helpful to engineers in designing this kind of structure.

\section{References}

[1] LI Xiao-zhen, CAI Jing, QIANG Shi-zhong. Studies on models of cable-girder anchorage for long-span cable-stayed bridges with steel box girder[J].Chinese Journal of Civil Engineering, 2004, 37(3):73-79. (in Chinese).

[2] YAN Hai,FAN Li-chu. Research on nonlinear contact problem of cable-beam anchorage for long-span cable-stayed bridge[J]. Chinese Journal of Highway and Transport,2004,17(2):46-49. (in Chinese).

[3] LIU Qing-kuan,WANG Xin-min,QIANG Shi-zhong. Full scale model test on anchorage zone of the second Yangtse River bridge at Nanjing[J]. Chinese Journal of Civil Engineering, 2001, 34(2):50-54. (in Chinese).

[4] ZHOU Xu-hong, LV Zhong-da, DI Jin, FAN Hong-jun. Analysis of ultimate bearing capacity on cable-girder anchorage zone of cable-stayed bridge with steel box girder. Chinese Journal of Chang'an University:Natural Science Edition,2007,27(3):47-51. (in Chinese). 